\title{
Research Article \\ Effect of Thermal Treatment on Fractals in Acoustic Emission of Rock Material
}

\author{
Z. Z. Zhang, ${ }^{1}$ X. L. Xu, ${ }^{1,2}$ Q. P. Sun, ${ }^{1}$ and Y. Dong ${ }^{1}$ \\ ${ }^{1}$ State Key Laboratory for Geomechanics and Deep Underground Engineering, School of Mechanics and Civil Engineering, \\ China University of Mining and Technology, Xuzhou 221116, China \\ ${ }^{2}$ School of Architecture and Civil Engineering, Nantong University, Nantong 226019, China \\ Correspondence should be addressed to Z.Z.Zhang; zzzcumt@163.com
}

Received 6 January 2016; Revised 29 February 2016; Accepted 7 March 2016

Academic Editor: Carlo Santulli

Copyright (C) 2016 Z. Z. Zhang et al. This is an open access article distributed under the Creative Commons Attribution License, which permits unrestricted use, distribution, and reproduction in any medium, provided the original work is properly cited.

\begin{abstract}
Acoustic emission (AE) series on time and location distributions on space are all fractal during the failure process of rock material. In this paper, $\mathrm{AE}$ signals of heated rock samples at different temperature under uniaxial compression were captured, and the correlation fractal dimensions (CFDs) of AE counts series at different stress level were calculated using Grassberger-Procaccia algorithm. The temperature effect on AE fractal behavior was revealed. The results show that as the heat temperature increases, the total AE counts are more, while the peak value is less. With the increase of external loading, the AE CFD increases fast to a peak at first and then decreases to a bottom and, after that, increases again but within a narrow range. $200^{\circ} \mathrm{C}$ and $800^{\circ} \mathrm{C}$ are two thresholds. As the heat temperature rises, the maximum CFD value and the corresponding stress level both increase from $25^{\circ} \mathrm{C}$ to $200^{\circ} \mathrm{C}$ and decrease from $200^{\circ} \mathrm{C}$ to $800^{\circ} \mathrm{C}$ and then increase again from $800^{\circ} \mathrm{C}$ to $1200^{\circ} \mathrm{C}$. The $\mathrm{CFD}$ value at the failure point shows polynomial decline with rising heat temperature.
\end{abstract}

\section{Introduction}

Acoustic emission (AE) is a nondestructive inspection technique, widely used for monitoring of crack growth behavior of rock [1,2]. It utilizes the transient elastic waves after each fracture occurrence, which are captured by sensors on the rock surface [3]. Several parameters of the AE behavior enlighten the damage stage within the rock material. These may be the cumulative AE counts, which is connected to the density of cracks and the emission energy which is connected to the cracks' intensity [4]. Additionally, $\mathrm{AE}$ waveform parameters like duration and frequency content depend on the motion of the crack tip and, therefore, carry information about the mode of the crack. Study of the AE indices enlightens the fracture process, enabling predictions on the rock deformation and failure $[5,6]$.

Researches show that the AE series on time and location distributions on space are all fractal $[7,8]$. Fractal theory provides an effective method to quantitatively analyze the complex AE indices, and some mechanical properties of rock can be expressed by fractal dimensions of AE data, which can develop some new applications. Guo et al. used the fractal dimension of AE location for quantitative evaluation of complexity of fracture network, and a novel "Soundless Cracking Agent (SCA) fracturing evaluation method" was developed [9]. Vinogradov et al. demonstrated that the fractal dimension of AE in a deforming material during uniaxial tensile deformation is an important quantitative characteristic of the evolution of the dislocation structure, and the peaking of fractal dimension signifies a nearing loss of uniformity of plastic flow and the onset of strain localization [10]. Gilyarov et al. analyzed AE data obtained at the rockburst-hazardous Antey deposit and proposed the correlation fractal dimension (CFD) of AE as a potential indication of rockburst accidents [11]. Iturrioz et al. got a quantitative evaluation of damage in concrete through the fractal dimension of $\mathrm{AE}$ signals distribution in the damaged domain [12]. Moustafa et al. presented a new approach based on fractal analysis of guided $\mathrm{AE}$ waves for monitoring the corrosion evolutionary path in posttensioned systems [13]. Invernizzi et al. confirmed that the energy dissipation during micro crack propagation in concrete occurs in a fractal domain [14]. Wang and Lin 


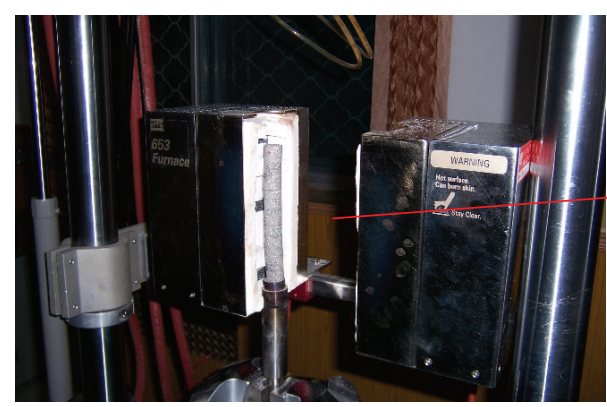

(a) MTS652.02

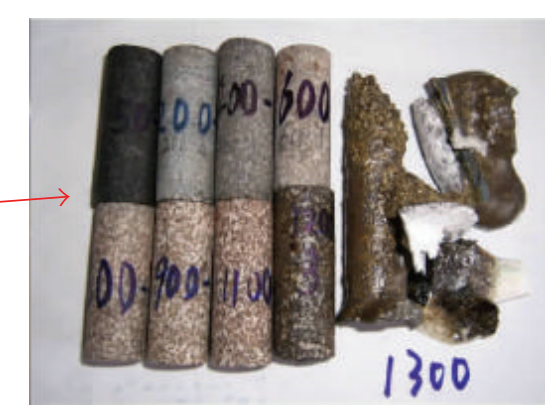

(b) Heated rock samples

FIGURE 1: MTS652.02 and heated rock samples.

studied fractal characteristics of cracking solids using $\mathrm{AE}$ and established the relationships between the stress ratio and dimensionless plastic zone size (PZS) with the fractal dimension [15]. Yuan and $\mathrm{Li}$ employed the box counting method (BCM) to calculate the fractal dimension of AEspatial distribution, and the results showed the fractal dimension presents a decreasing trend with the increase of load strength [16]. Majewska and Mortimer studied the nonlinear dynamics of AE generated in coal samples subjected to gas sorption-desorption by analysis of fractal generalised dimensions and fractal correlation dimension of $\mathrm{AE}$ energy rate [17]. Zhou and Liu tested AE in rock specimen under loading and breakage and calculated the CFD and the maximum Lyapunov exponents according to the recorded $\mathrm{AE}$ data, based on which the chaotic kinetics laws of $\mathrm{AE}$ in rocks are obtained [18]. Wu et al. found that the evolutions of the fractal dimension of $\mathrm{AE}$ during failure can be divided into a mode of "fluctuation-gradual descending," and the descent of the fractal dimension can be regarded as the precursor information to predict the collapse of the rock masses [19]. Zhang et al. calculated the fractal dimension of $\mathrm{AE}$ by the method of correlation dimension algorithm, and it increases at the initial stage and then decreases [20].

It is known that temperature plays an important role in mechanical and AE behavior of rock material [21, 22], which has been studied widely in former literature. However, the effect of high temperature on the fractal characteristics in $\mathrm{AE}$ data during rock deformation has not been investigated. In the present study, we first captured the AE signals of rock samples after heat treatment at different temperature during uniaxial compression process and then used GrassbergerProcaccia algorithm to calculate the $\mathrm{CFD}$ of $\mathrm{AE}$ counts series at every stress level. The results can deepen our understanding of temperature effect on $\mathrm{AE}$ behavior and can offer useful viewpoint to predict rock failure in high temperature environment.

\section{Experimental Procedures}

2.1. Preparation of Rock Specimens. Granite in this experiment is collected from Yanzhou mining area, Shandong Province (China), and it is mainly composed of feldspar, illite, pyroxene, and small amounts of other minerals. Limited to cubage of the heater and according to ISRM rock testing advice, rock specimens were processed into cylinder with diameter $25 \mathrm{~mm}$ and height $50 \mathrm{~mm}$. After carefully grinding on both upper and lower surface of rock samples using slice machine and sand paper, we make the specimens' parallelism of the upper-lower surface fluctuate within $0.05 \mathrm{~mm}$ and the flatness of the surface within $0.02 \mathrm{~mm}$. The longitudinal wave velocity through the rock specimens value is about $4500 \mathrm{~m} / \mathrm{s}$ under $25^{\circ} \mathrm{C}$, so the integrity and uniformity perform relatively well. Moreover, the average density of this kind of granite is $2.76 \mathrm{~g} / \mathrm{cm}^{3}$ in $25^{\circ} \mathrm{C}$, while the average uniaxial compressive strength is $191.9 \mathrm{MPa}$.

2.2. Testing Equipment and Methods. We mainly conduct the tests of uniaxial compression on rock specimens, which have naturally cooled to room temperature after heat treatment at different temperature. There were 6 groups, $25^{\circ} \mathrm{C}, 200^{\circ} \mathrm{C}$, $500^{\circ} \mathrm{C}, 800^{\circ} \mathrm{C}, 1000^{\circ} \mathrm{C}$, and $1200^{\circ} \mathrm{C}$, with 3 specimens in each group.

Firstly, we heated the specimens, respectively, to a predetermined temperature with the heating rate of $2^{\circ} \mathrm{C}$ per minute using the high temperature furnace MTS652.02 (shown in Figure 1(a)); then, according to the actual experience of foreign scholars, the heating process lasts 20 minutes to make sure the specimens are heated evenly; finally, let the heated rock specimens cool naturally to the room temperature (shown in Figure 1(b)).

In this experiment, we used the electric hydraulic servovalve control system of MTS815.02 at the State Key Laboratory for Geomechanics and Deep Underground Engineering of CUMT to apply load (see Figure 2(a)) and used PCI-2 AE Detector (see Figure 2(b)) to catch AE signals during rock deformation and failure. The displacement control mode was applied in the process of rock loading, with the loading rate of $0.0015 \mathrm{~mm} / \mathrm{s}$; meanwhile, the control program TestStar II was also used to finish this experiment and record the values of related parameters.

\section{Results and Discussion}

3.1. Stress-Strain Curves. The whole stress-strain curves of rock material under uniaxial compression after high temperature are shown in Figure 3. The shapes of the curves 


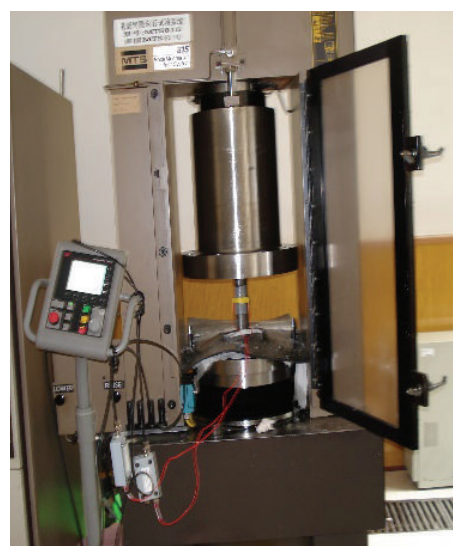

(a) MTS815.02

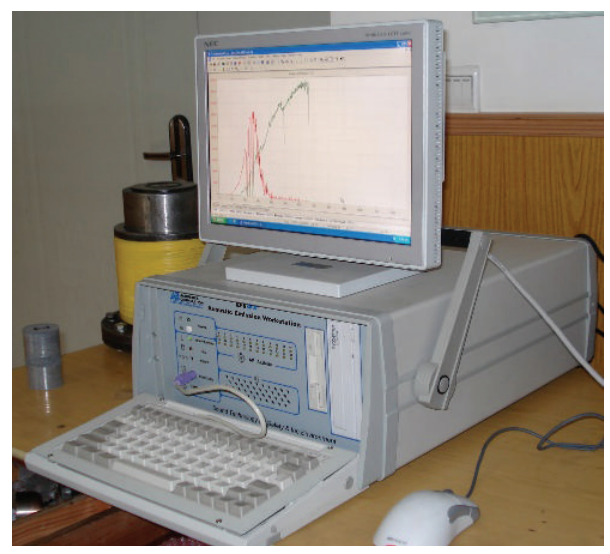

(b) PCI-2

Figure 2: Appearance of MTS815.02 System and PCI-2 AE Detector.

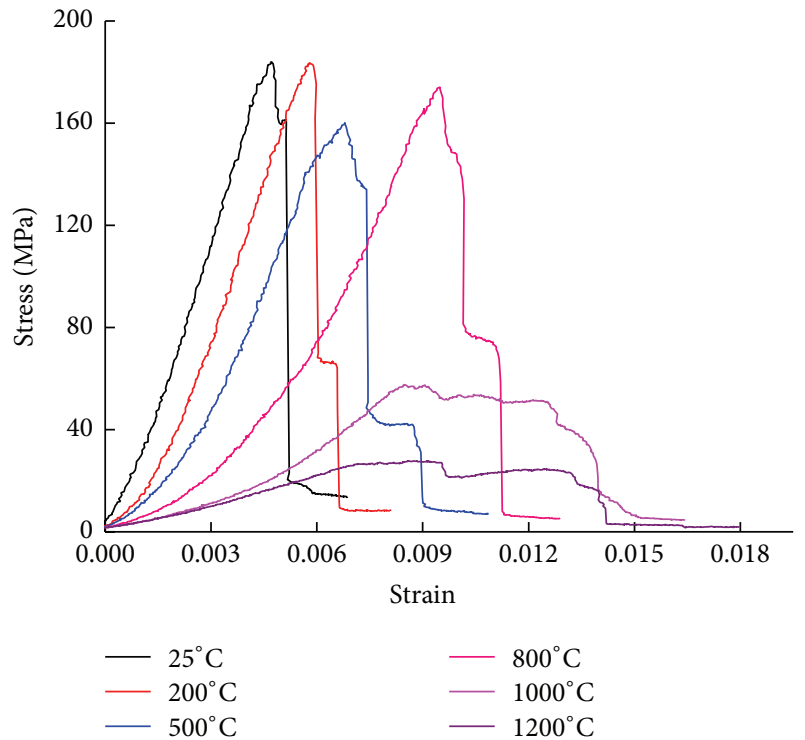

FIGURE 3: The whole stress-strain curves of rock samples after different temperature.

are similar in rough, and this can be divided into four evident stages, that is, compaction stage, elastic stage, weak stage, and failure stage. Moreover, several obvious differences among them exist. When the heat temperature is higher, the strain ranges corresponding to the compaction and weak stage are bigger, while the elastic stage is shorter, especially between $800^{\circ} \mathrm{C}$ and $1200^{\circ} \mathrm{C}$. On the other hand, the lower temperature samples present brittleness damage, and plastic fracture characteristics show more greatly when the heat temperature is more than $800^{\circ} \mathrm{C}$.

From the stress-strain curves, we can obtain the uniaxial compressive strength (UCS) of rock samples under different temperature. The variation of UCS with temperature can be seen in Figure 4. Although the values of UCS are of high discreteness, the mean value presents obvious law that the UCS decreases generally as the temperature rises. Furthermore, it falls gently before $800^{\circ} \mathrm{C}$, while a rapid drop shows then, and the rock samples lose their compressive capacity when the temperature reaches $1200^{\circ} \mathrm{C}$.

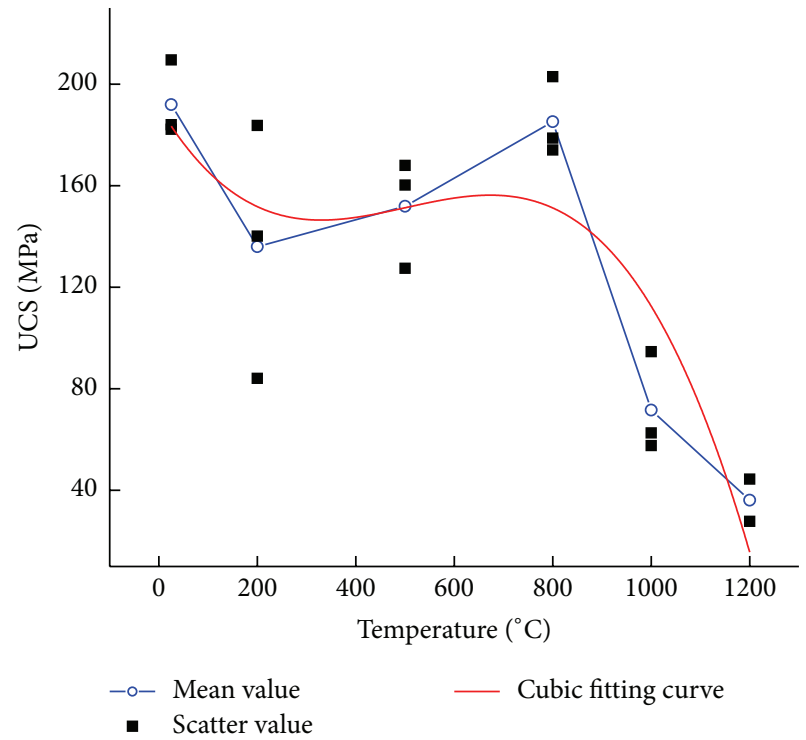

FIGURE 4: Variation of UCS of rock samples with increasing temperature.

Elastic modulus is one of the essential mechanical parameters, and it also can be calculated by stress-strain curve. Figure 5 shows the variation of elastic modulus with temperature under uniaxial compression. It expresses that the elastic modulus decreases gradually as the temperature rises, and the downward gradient keeps stable in the temperature range, which is different from that the UCS shows.

Water evaporation at the higher heat temperature generates more pores, and nonuniformity in mineral inflation caused by high temperature brings more damage during cooling process [23]. These are two reasons for the differences on deformation and failure behaviors under different temperature.

3.2. AE Curves during Loading Process. Strain energy accumulates during rock deformation induced by loading or unloading, and the accumulated energy will be released as elastic wave after crack occurrence, which is called AE [1]. 


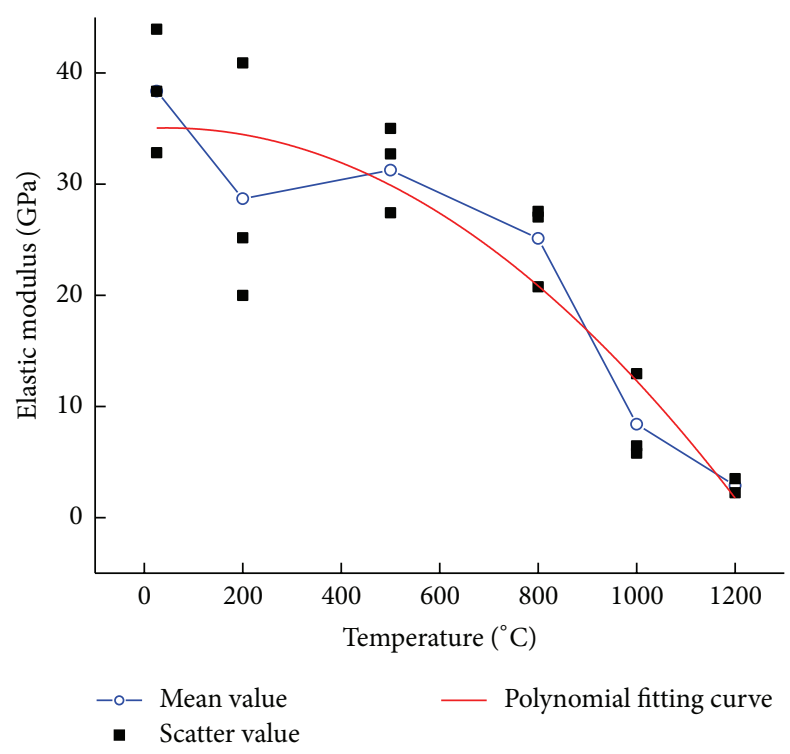

FIGURE 5: Variation of elastic modulus of rock samples with increasing temperature.

Thus we can get the crack distribution and extension from $\mathrm{AE}$ signals detected. The AE counts-strain curves together with stress-strain curves at six different temperatures are shown in Figure 6. The AE curves correspond to the stress-strain curves well, and the peak values of $\mathrm{AE}$ counts always follow the stress drop, which mean energy release suddenly.

The whole AE curve can be divided into six stages in rough, which are initial quiet stage (IQS), rising stage (RS), first peak stage (FPS), continuous stage (CS), second peak stage (SPS), and last quiet stage (LQS). In IQS, AE signal is very weak and can be hardly detected, which indicates no obvious damage is produced. As the loading goes up, $\mathrm{AE}$ counts begin to occur steadily with small ascensional range, which lasts for a long while, and we call this stage RS. IQS and RS correspond to compaction stage and elastic stage on stress-strain curve, respectively. The following three stages, FPS, CS, and SPS, together make an intense AE period, in which AE signals emerge in large numbers. The FPS occurs at the transitory period from elastic stage to weak stage on stress-strain curve, because damage in rock samples initiates amounts of micro cracks, and strain energy accumulated in former stage is released suddenly. Then $\mathrm{AE}$ events last actively because of crack growth, and that is CS. When cracks finally coalesce into macrocrack, rock samples can not bear the applied load, and the stress reaches the UCS of the rock material. The accumulated energy before the peak stress is released sharply and largely, and the peak value of AE counts during the whole loading process is made. This stage is named SPS. After that, AE signal does not disappear for residual fracture, but it drops greatly, and another relatively quiet period comes, called LQS.

At $25^{\circ} \mathrm{C}$, IQS, RS, and LQS exist obviously, while FPS, CS, and SPS combine together. That is because the rock samples at $25^{\circ} \mathrm{C}$ are hard and brittle, and the time of crack initiation, propagation, and coalescence is shorter relatively, which leads to concentrated $\mathrm{AE}$ counts. As the heat temperature rises, crack growth lasts longer time, and the strain energy is released differently in each stage, and the six AE stages become distinguishable. Rock samples heated at higher temperature show more plastic, and the AE events in FPS, CS, and SPS are more active, but the strength of AE energy is lower. As the heat temperature increases, the total $\mathrm{AE}$ counts are more, while the peak value is less.

\section{Fractals in AE Behavior}

There exists very close relation between the phenomenon of $\mathrm{AE}$ and rock fracture, and the $\mathrm{AE}$ curve during the whole loading process expresses the growth of cracks in rock samples $[4,6]$. Through the above analysis, we get some qualitative results on $\mathrm{AE}$ characters of heated rock samples at different high temperature under uniaxial compression. The $\mathrm{AE}$ signals are unordered and complex time series relatively; we can use fractal theory to analyze them quantificationally to find new viewpoints.

4.1. Grassberger-Procaccia Algorithm. Grassberger-Procaccia method offers a widely applicable way to calculate the CFD of a series of numbers [7]. AE counts during rock deformation and failure under uniaxial compression can be regarded as such a series of numbers. A series whose dimension is $n$ can be expressed as

$$
X=\left\{x_{1}, x_{2}, \ldots, x_{n}\right\} .
$$

We can construct a phase space with $m$ dimension based on $X(m<n)$. Firstly, take $m$ numbers out from $X$ continuously to build the first vector $X_{1}$ :

$$
X_{1}=\left\{x_{1}, x_{2}, \ldots, x_{m}\right\} .
$$

Then, move right one number; the second vector including $m$ numbers could be gotten:

$$
X_{2}=\left\{x_{2}, x_{3}, \ldots, x_{m+1}\right\} .
$$

We can get $n-m+1$ vectors finally, and the last one is

$$
X_{n-m+1}=\left\{x_{n-m+1}, x_{n-m+2}, \ldots, x_{n}\right\} .
$$

The correlation function is

$$
W(r)=\frac{1}{N^{2}} \sum_{i=1}^{N} \sum_{j=1}^{N} H\left[r-\left|X_{i}-X_{j}\right|\right] .
$$

Here, $N$ is equal to $n-m+1, H$ is the Heaviside function, $r$ is certain measure, and $\left|X_{i}-X_{j}\right|$ expresses the distance between vectors of $X_{i}$ and $X_{j}$ :

$$
\begin{aligned}
H(u) & = \begin{cases}0, & u<0 \\
1, & u \geq 0,\end{cases} \\
r & =k r_{0}=k \frac{1}{N^{2}} \sum_{i=1}^{N} \sum_{j=1}^{N}\left|X_{i}-X_{j}\right| .
\end{aligned}
$$

Here, $k$ is a scale coefficient. 


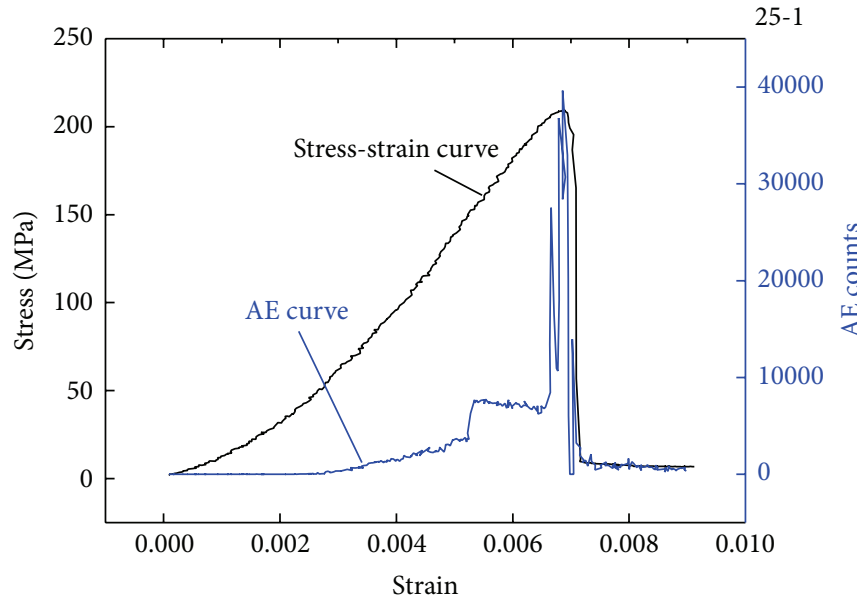

(a) $25^{\circ} \mathrm{C}$

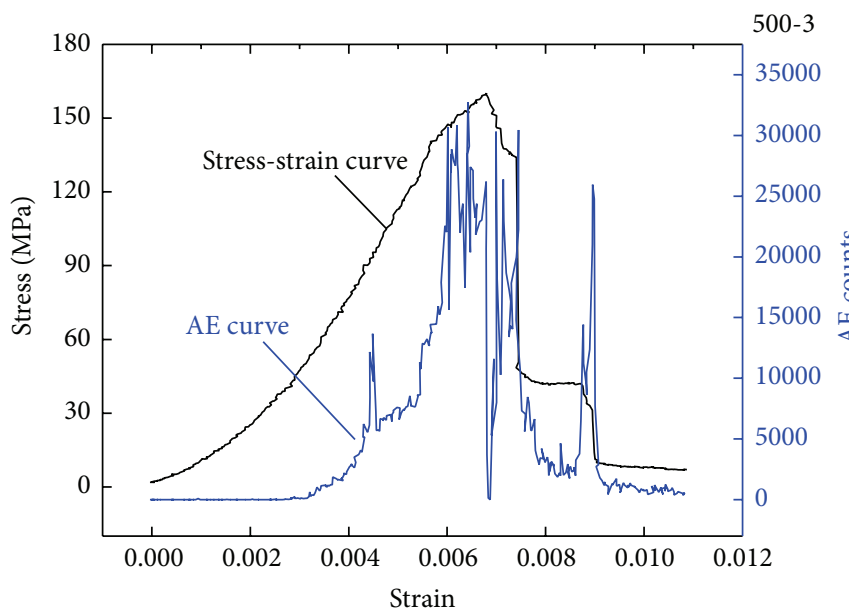

(c) $500^{\circ} \mathrm{C}$

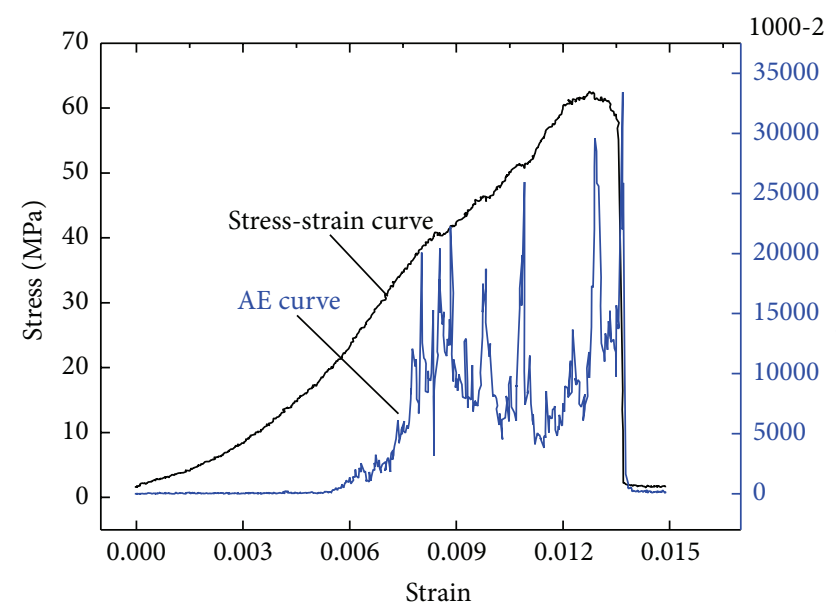

(e) $1000^{\circ} \mathrm{C}$

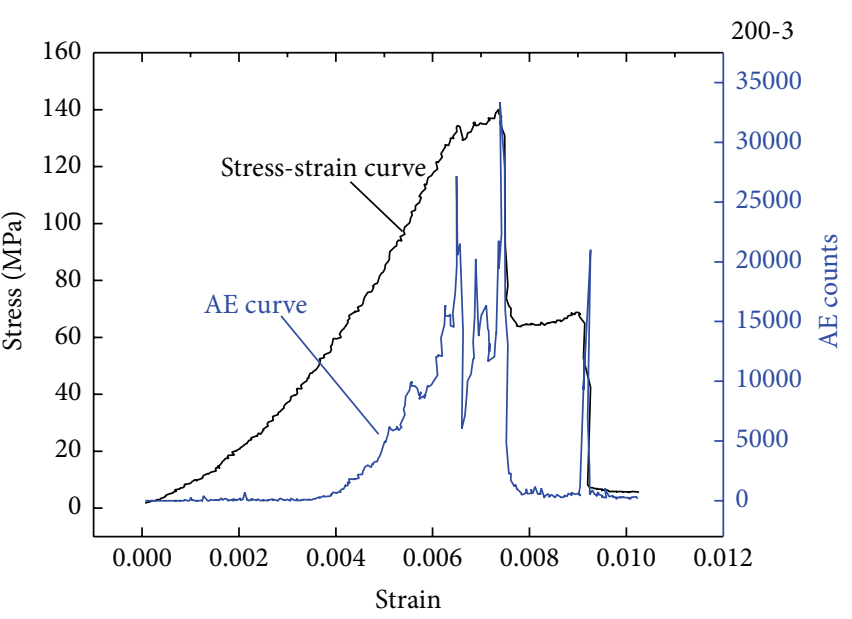

(b) $200^{\circ} \mathrm{C}$

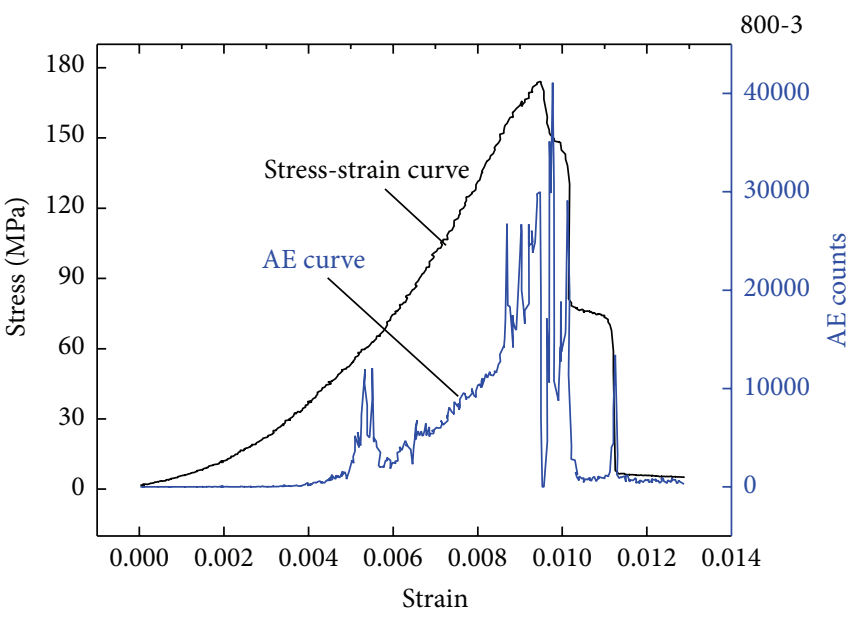

(d) $800^{\circ} \mathrm{C}$

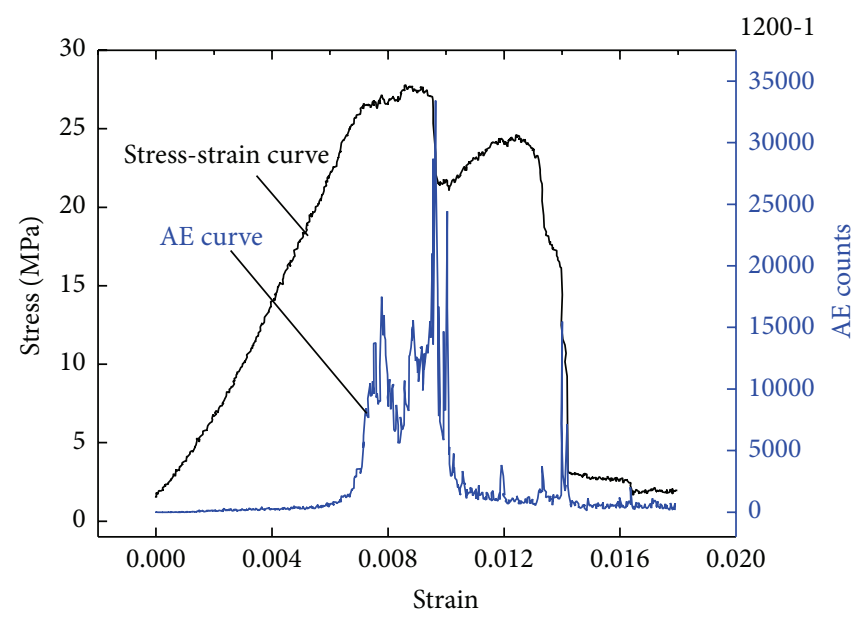

(f) $1200^{\circ} \mathrm{C}$

FIGURE 6: Relationship between stress-strain curve and AE counts after different temperature. 


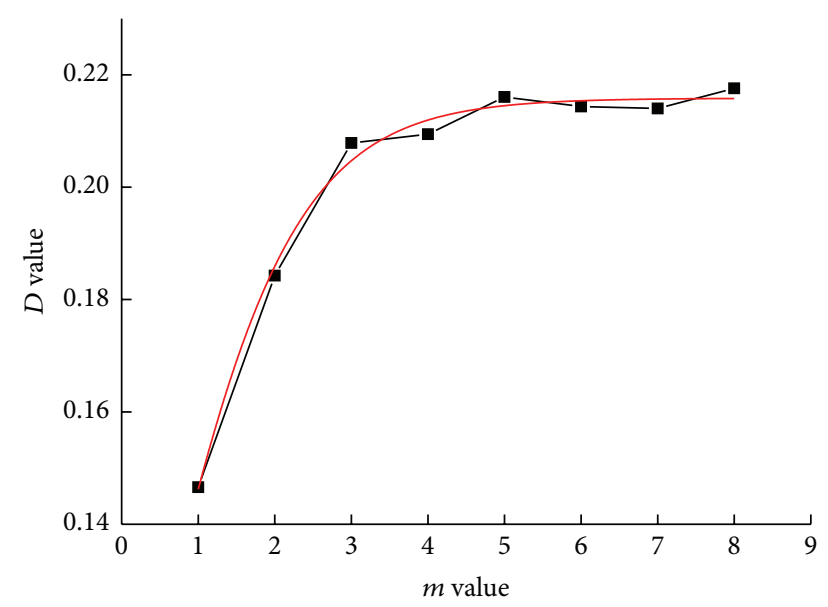

FIgURE 7: Variation of fractal dimension $D$ value with $m$ value at $25^{\circ} \mathrm{C}$.

From the above equations, we can get one value of $W(r)$ corresponding to one value of $r$, so several data pairs of $r$ and $W(r)$ could be obtained. If they follow linear relation in double logarithmic coordinates, the series is fractal, and the CFD $D$ equals the slope value of $\lg r-\lg W(r)$ curve:

$$
D=\frac{\lg W(r)}{\lg r} .
$$

According to definition of the CFD $D$, we can know its physical significance for AE series. Larger value of $D$ indicates that fractures in rock sample are more chaotic in time, and over half of them are micro ones. On the contrary, if the value of $D$ is small, fractures trend to be well organized and strongly localized and main rupture would be developed.

4.2. Determination of $m$ Value. Determination of $m$ value has an important effect in computation of $D$ value. Too small value would result in no attractor cross to distinguish lower dimension, and too big value would lead to more noise. Researches show that $D$ value becomes larger with increasing $m$ value until $m$ reaches a certain value, and then $D$ keeps stable $[6,7,19,20]$. The certain $m$ value should be selected to calculate $D$ value.

Take $\mathrm{AE}$ counts series at $25^{\circ} \mathrm{C}$, for example; the changing curve of $D$ value with $m$ is shown in Figure 7. The CFD $D$ rises from 0.14 to 0.22 when $m$ value changes from 1 to 5 , and then $D$ value holds steady although $m$ increases, and they follow sigmoidal logistic function. So 5 was chosen as the $m$ value for calculating the $\mathrm{CFD}$ at $25^{\circ} \mathrm{C}$.

The $m$ values at different heat temperature were found according to the same way, and they can be seen in Figure 8 . The results show that the $m$ value and the heat temperature follow Gauss function, and the $m$ value becomes bigger as the temperature rises before $800^{\circ} \mathrm{C}$, while it shows the exact contrary over $800^{\circ} \mathrm{C}$.

4.3. AE CFDs at Different Stress Level under Each Heat Temperature. For each $\mathrm{AE}$ series at different heat temperature, according to (1)-(7), we calculated the $D$ values at 10 typical

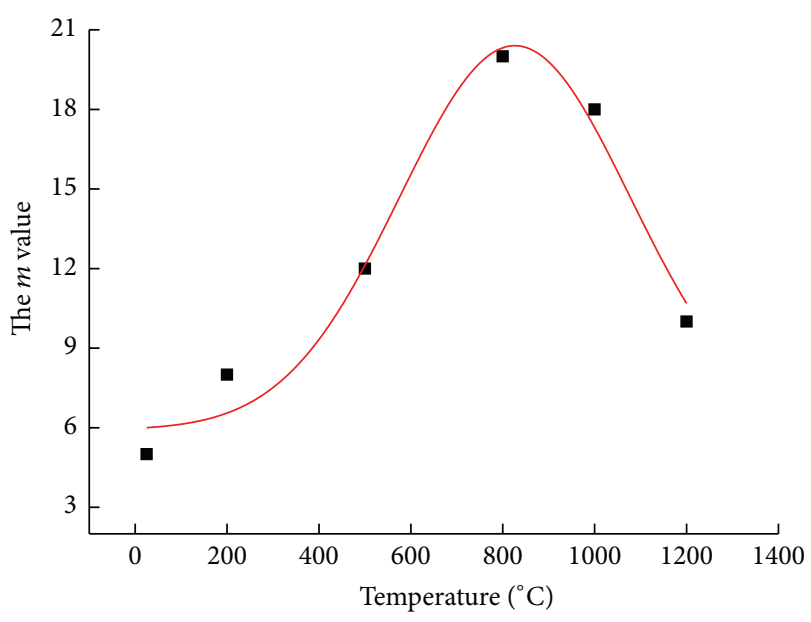

FIGURE 8: Variation of the $m$ value with increasing heat temperature.

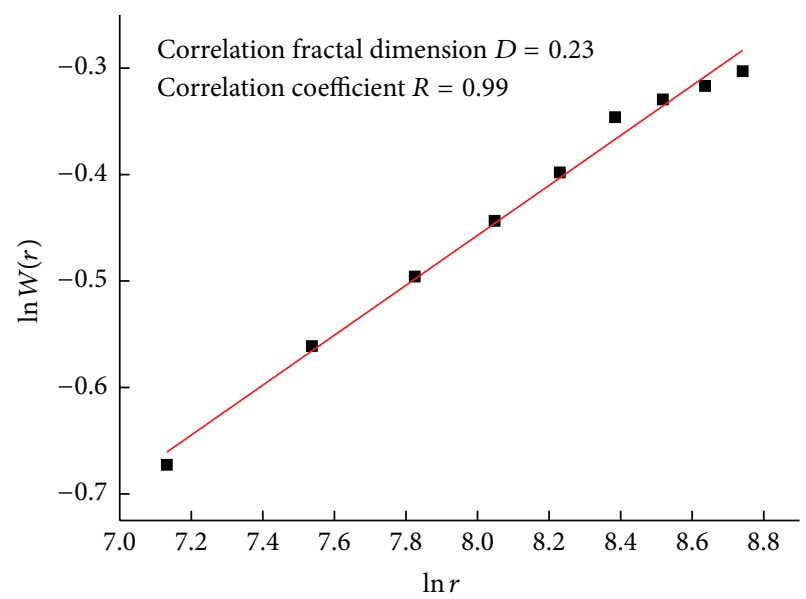

Figure 9: Calculation of CFD at stress level $40 \%$ under $800^{\circ} \mathrm{C}$.

stress levels between $10 \%$ and $100 \%$ in prepeak stage to investigate the changing law of CFD during the whole loading process.

Take the stress level $40 \%$ at $800^{\circ} \mathrm{C}$ as an example; the data pairs of $\ln r$ and $\ln W(r)$ are shown in Figure 9. Fit them by using linear function, and the $D$ value is equal to the slope of the fitting straight line. For each stress level under every heat temperature, we did the same calculation, and the fitting correlation coefficients are all over $90 \%$, which indicates that $\mathrm{AE}$ counts series of rock material under uniaxial compression after heating are fractal and have self-similarity very well.

Variation of the $D$ value with increasing stress level before peak strength under six heat temperatures is shown in Figure 10. The curve patterns from $25^{\circ} \mathrm{C}$ to $1000^{\circ} \mathrm{C}$ are similar, and the $D$ value increases fast to a peak at first and then decreases to a bottom and, after that, increases again but within a narrow range. The $D$ evolution curve after $1200^{\circ} \mathrm{C}$ is an exception, and the second increasing stage does not exist.

Numbers of micro cracks with different sizes grow randomly at low stress level, which shows chaos and randomness. It corresponds to the first increasing stage of $D$ value. As the stress increases, crack growth trends to the same direction 


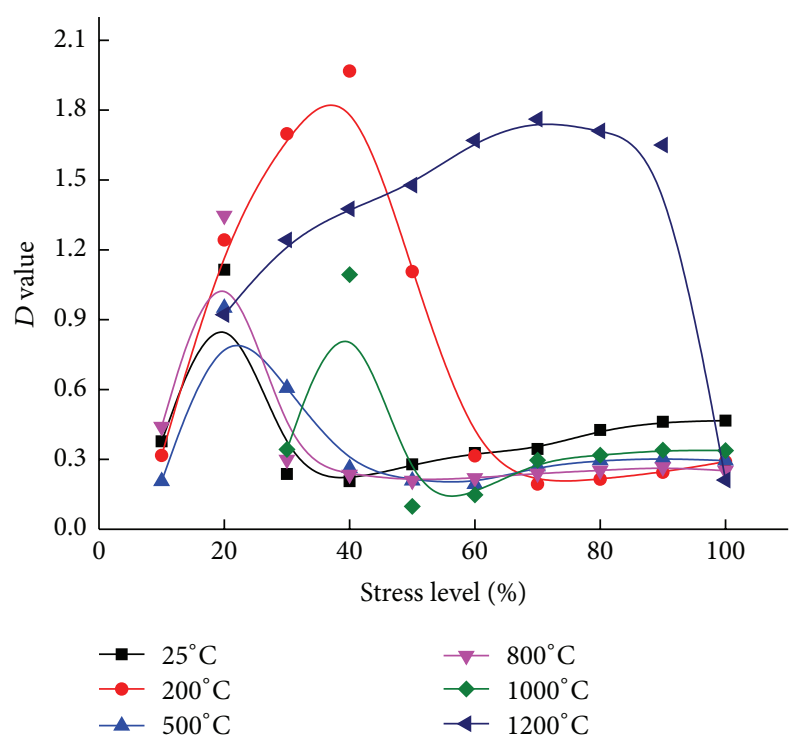

FIGURE 10: Variation of the CFD with increasing stress level after different heat temperature.

and converts to regular fracture, and this corresponds to the decreasing stage of $D$ value. The stress increase proceeds, and the rock structure adjusts again, and the $D$ value rises a little. This new adjustment would lead to the final main fracture at the peak stress level.

4.4. The Maximum and Minimum Values of CFD D. According to the $D$ curve pattern, we focus on two points on the curve, that is, the maximum value and the minimum one. The maximum value means the most chaotic state during the loading process, and the micro cracks are random, while the minimum value refers to the most organized state before peak strength, which indicates that the disorderly cracks would be connected with each other by stress field and form a preliminary organic whole. The second increasing stage shows that the rock structure readjusts and cracks grow disorderly again, but the $D$ value increases small, which expresses that the randomness would be weakened greatly by the first adjustment. The whole loading process is a complicated period of chaos and order.

The maximum and minimum $D$ values after different temperatures are shown in Figure 11. The curves express that the minimum $D$ values are all about 0.2 , but the maximum values differ greatly. As the heat temperature rises, the maximum $D$ value increases from $25^{\circ} \mathrm{C}$ to $200^{\circ} \mathrm{C}$ and decreases from $200^{\circ} \mathrm{C}$ to $800^{\circ} \mathrm{C}$ and then increases again from $800^{\circ} \mathrm{C}$ to $1200^{\circ} \mathrm{C}$. $200^{\circ} \mathrm{C}$ and $800^{\circ} \mathrm{C}$ are two thresholds, which can be verified by former researches [23].

In fact, the randomness of $\mathrm{AE}$ events or cracks mainly depends on the homogeneity of rock material, and stronger homogeneity would lead to greater randomness [24]. When the heat temperature is between $25^{\circ} \mathrm{C}$ and $200^{\circ} \mathrm{C}$, the mineral moisture evaporation increases the homogeneity of small openings. From $200^{\circ} \mathrm{C}$ to $800^{\circ} \mathrm{C}$, higher temperature makes different minerals swell unequally, and more damage is

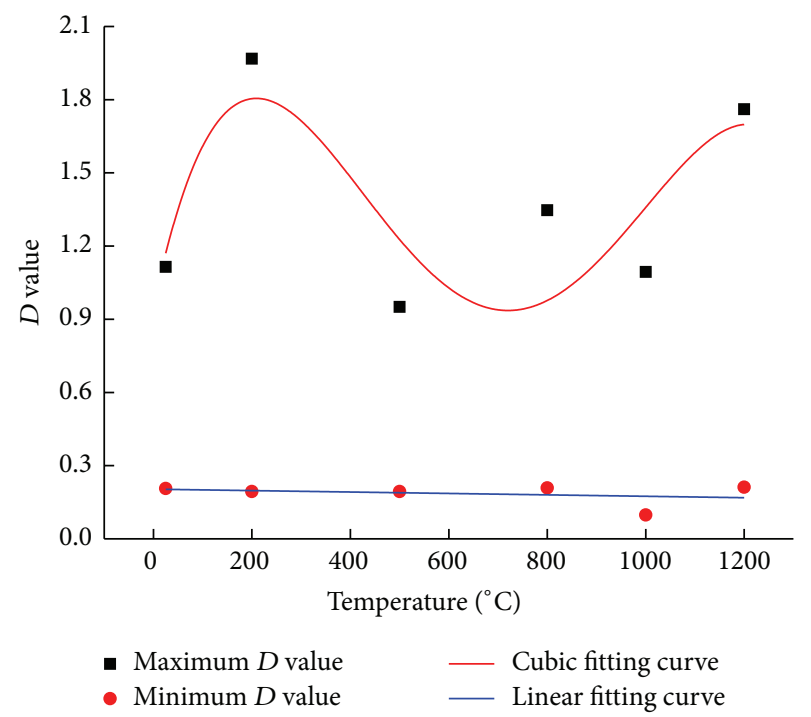

FIgURE 11: The maximum and minimum $D$ values before peak strength after different temperatures.

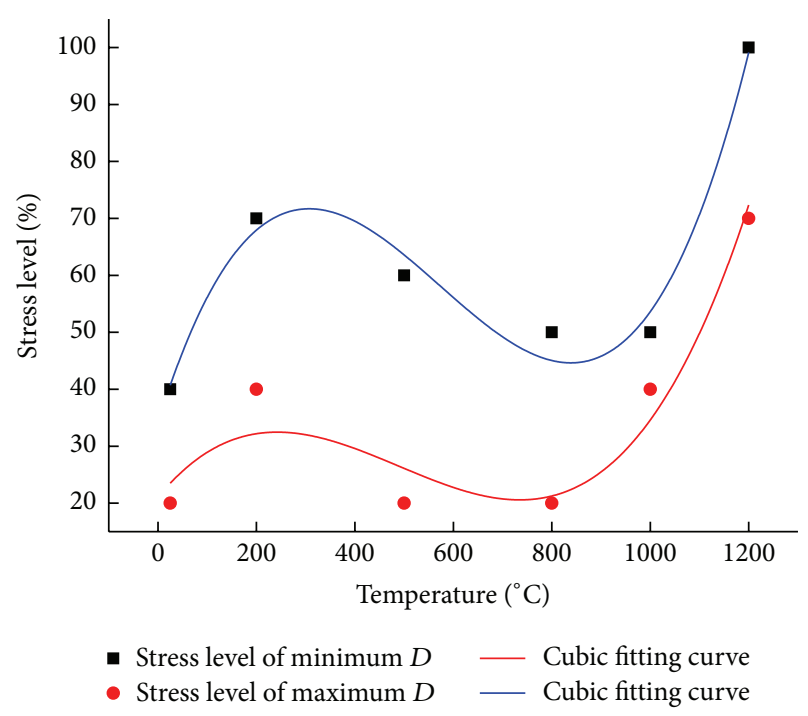

FIGURE 12: The stress levels corresponding to maximum and minimum $D$ values at different temperatures.

produced by residual stress during natural cooling process, so the homogeneity becomes stronger. When the temperature exceeds $800^{\circ} \mathrm{C}$, rock minerals change phases [25], and the mechanical property turns to plasticity from brittleness, and the homogeneity gets stronger and stronger. That is why the maximum $D$ value changes that way in Figure 11 with increasing heat temperature.

To find when the maximum and minimum $D$ values reach is significative for predicting rock deformation and failure. The stress levels corresponding to maximum and minimum $D$ values under different temperatures are shown in Figure 12. The two curves show that they all follow cubic function, and $200^{\circ} \mathrm{C}$ and $800^{\circ} \mathrm{C}$ are also two thresholds. The corresponding stress level increases, decreases, and then increases again 


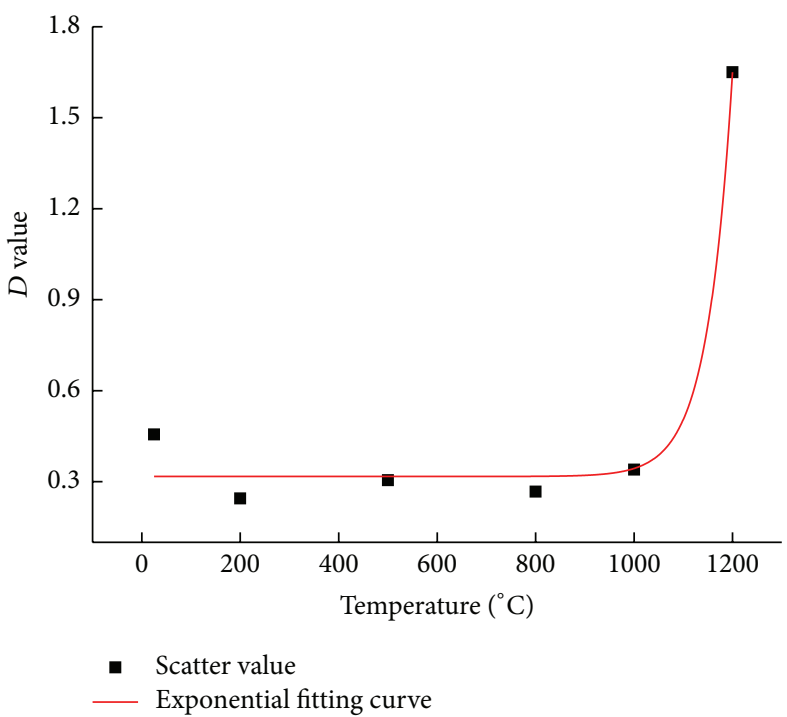

(a) Stress level $=90 \%$

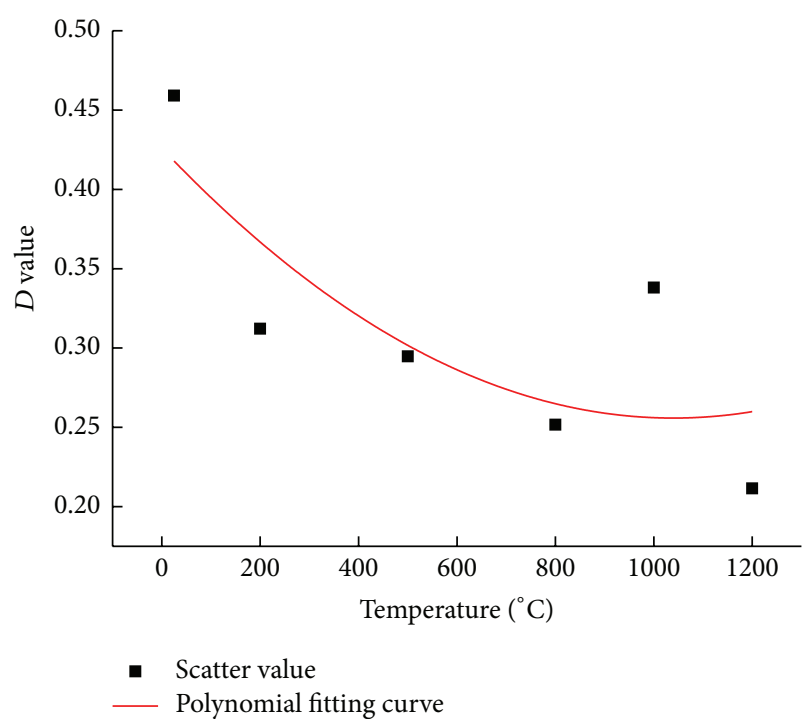

(b) Stress level $=100 \%$

Figure 13: The effect of heat temperature on the $D$ value at stress levels $90 \%$ and $100 \%$.

in the interval of $25-200^{\circ} \mathrm{C}, 200-800^{\circ} \mathrm{C}$, and $800-1200^{\circ} \mathrm{C}$, respectively.

According to the above analysis, the higher corresponding stress level indicates that the rock material is more homogeneous and brittle. On one hand, the first period of chaos lasts long for rock material with better homogeneity because the lack of inherent defect results in randomness, so the stress level corresponding to the maximum $D$ value is higher. For example, the corresponding stress level is $40 \%$ for $200^{\circ} \mathrm{C}$ but $20 \%$ for $800^{\circ} \mathrm{C}$. On the other hand, the stress applied on the more homogeneous rock sample would be higher when the $D$ value reaches the minimum; with the same reason, it is difficult to generate dominant crack because of less inherent defect. For example, the corresponding stress level is $70 \%$ for $200^{\circ} \mathrm{C}$, while it is $50 \%$ for $800^{\circ} \mathrm{C}$.

4.5. CFD D Values near Rock Failure under Different Heat Temperature. Analysis of the $D$ value near peak strength is helpful to obtain the effect law of temperature on rock failure characteristics. We selected two stress levels, $90 \%$ and $100 \%$, to discuss the failure characteristics under different temperature, and the $D$ curves are shown in Figure 13.

At the stress level $90 \%$, the $D$ value and heat temperature are fitted to the exponential function. The $D$ value is around 0.3 when the heat temperature is less than $1000^{\circ} \mathrm{C}$, while it increases by more than 4 times under $1200^{\circ} \mathrm{C}$. This curve indicates that high temperature makes $\mathrm{AE}$ events chaotic near failure. Furthermore, when the stress level reaches $100 \%$, that is, the failure point, the $D$ value shows polynomial decline with rising temperature, which indicates the AE events in rock sample that had undergone higher temperature become more regular at failure point. Comparing the two curves, also we find that the difference value of $D$ between stress levels $90 \%$ and $100 \%$ rises with heat temperature, and the larger difference value makes rock failure more predictable, so the $D$ value can be used as the precursor of rock failure prediction.

\section{Conclusions}

Experiments of heated rock samples at different temperature under uniaxial compression were conducted, and the results and discussion show the following:

(1) Rock samples heated at higher temperature show more plastic. The uniaxial compressive strength (UCS) of rock samples decreases gently before $800^{\circ} \mathrm{C}$, while a rapid drop shows from $800^{\circ} \mathrm{C}$ to $1200^{\circ} \mathrm{C}$. The elastic modulus decreases gradually as the temperature rises, and the downward gradient keeps stable.

(2) The whole AE curve can be divided into six stages in rough, which are initial quiet stage (IQS), rising stage (RS), first peak stage (FPS), continuous stage (CS), second peak stage (SPS), and last quiet stage (LQS). As the heat temperature increases, the total AE counts are more, while the peak value is less.

(3) AE counts series of rock material under uniaxial compression after heating are fractal and have selfsimilarity very well. With the increase of external loading, the AE CFD increases fast to a peak at first and then decreases to a bottom and, after that, increases again but within a narrow range.

(4) $200^{\circ} \mathrm{C}$ and $800^{\circ} \mathrm{C}$ are two thresholds. As the heat temperature rises, the maximum $D$ value and the corresponding stress level both increase from $25^{\circ} \mathrm{C}$ to $200^{\circ} \mathrm{C}$ and decrease from $200^{\circ} \mathrm{C}$ to $800^{\circ} \mathrm{C}$ and then increase again from $800^{\circ} \mathrm{C}$ to $1200^{\circ} \mathrm{C}$.

(5) The $D$ value increases exponentially with rising heat temperature near rock failure and shows polynomial decline at the failure point. The $D$ value can be used as the precursor of rock failure prediction. 


\section{Abbreviation Index}

CFD: Correlation fractal dimension

AE: Acoustic emission

PZS: Plastic zone size

BCM: Box counting method

UCS: Uniaxial compressive strength

IQS: Initial quiet stage

RS: Rising stage

FPS: First peak stage

CS: Continuous stage

SPS: Second peak stage

LQS: Last quiet stage.

\section{Competing Interests}

The authors declare that they have no competing interests.

\section{Acknowledgments}

Financial supports for this work, provided by the Fundamental Research Funds for the Central Universities (no. 2014QNA80), the Natural Science Foundation of Jiangsu Province (no. BK20140189), and a Project Funded by the Priority Academic Program Development (PAPD) of Jiangsu Higher Education Institutions, are gratefully acknowledged.

\section{References}

[1] S. Q. Qin, Z. D. Li, and Z. Y. Zhang, Introduction to Rock Acoustic Emission Technique, Southwest Jiaotong University Press, Chengdu, China, 1993.

[2] L.-H. Chen, W.-C. Chen, Y.-C. Chen, L. Benyamin, and A.$\mathrm{J}$. Li, "Investigation of hydraulic fracture propagation using a post-peak control system coupled with acoustic emission," Rock Mechanics and Rock Engineering, vol. 48, no. 3, pp. 1233-1248, 2015.

[3] A. Carpinteri, G. Lacidogna, F. Accornero, A. C. Mpalaskas, T. E. Matikas, and D. G. Aggelis, "Influence of damage in the acoustic emission parameters," Cement and Concrete Composites, vol. 44, pp. 9-16, 2013.

[4] C. D. Zhang, W. G. Liang, Z. G. Li, S. G. Xu, and Y. S. Zhao, "Observations of acoustic emission of three salt rocks under uniaxial compression," International Journal of Rock Mechanics and Mining Sciences, vol. 77, pp. 19-26, 2015.

[5] Z.-Z. Zhang, F. Gao, and X.-J. Shang, "Rock burst proneness prediction by acoustic emission test during rock deformation," Journal of Central South University, vol. 21, no. 1, pp. 373-380, 2014.

[6] C. Khazaei, J. Hazzard, and R. Chalaturnyk, "Damage quantification of intact rocks using acoustic emission energies recorded during uniaxial compression test and discrete element modeling," Computers and Geotechnics, vol. 67, pp. 94-102, 2015.

[7] F. Gao, J. Li, and X. Li, "Fractal analysis of the characteristics of acoustic emission of rock," Journal of Wuhan University of Technology, vol. 27, no. 7, pp. 67-69, 2005.

[8] H. P. Xie, J. F. Liu, Y. Ju, J. Li, and L. Z. Xie, "Fractal property of spatial distribution of acoustic emissions during the failure process of bedded rock salt," International Journal of Rock Mechanics and Mining Sciences, vol. 48, no. 8, pp. 1344-1351, 2011.
[9] T. Guo, S. Zhang, H. Ge, X. Wang, X. Lei, and B. Xiao, "A new method for evaluation of fracture network formation capacity of rock," Fuel, vol. 140, pp. 778-787, 2015.

[10] A. Vinogradov, I. S. Yasnikov, and Y. Estrin, "Stochastic dislocation kinetics and fractal structures in deforming metals probed by acoustic emission and surface topography measurements," Journal of Applied Physics, vol. 115, no. 23, Article ID 233506, 2014.

[11] V. L. Gilyarov, E. E. Damaskinskaya, A. G. Kadomtsev, and I. Y. Rasskazov, "Analysis of statistic parameters of geoacoustic monitoring data for the Antey uranium deposit," Journal of Mining Science, vol. 50, no. 3, pp. 443-447, 2014.

[12] I. Iturrioz, G. Lacidogna, and A. Carpinteri, "Acoustic emission detection in concrete specimens: experimental analysis and lattice model simulations," International Journal of Damage Mechanics, vol. 23, no. 3, pp. 327-358, 2014.

[13] A. Moustafa, E. D. Niri, A. Farhidzadeh, and S. Salamone, "Corrosion monitoring of post-tensioned concrete structures using fractal analysis of guided ultrasonic waves," Structural Control \& Health Monitoring, vol. 21, no. 3, pp. 438-448, 2014.

[14] S. Invernizzi, G. Lacidogna, and A. Carpinteri, "Scaling of fracture and acoustic emission in concrete," Magazine of Concrete Research, vol. 65, no. 9, pp. 529-534, 2013.

[15] H. J. Wang and Z. Lin, "Detection of fractal characteristics based on acoustic emission," Materials Science and Technology, vol. 29, no. 2, pp. 240-249, 2013.

[16] R.-F. Yuan and Y.-H. Li, "Fractal analysis on the spatial distribution of acoustic emission in the failure process of rock specimens," International Journal of Minerals, Metallurgy and Materials, vol. 16, no. 1, pp. 19-24, 2009.

[17] Z. Majewska and Z. Mortimer, "Chaotic behaviour of acoustic emission induced in hard coal by gas sorption-desorption," Acta Geophysica, vol. 54, no. 1, pp. 50-59, 2006.

[18] X.-P. Zhou and Q.-Y. Liu, "Research on chaotic characteristics of rock acoustic emission," Rock and Soil Mechanics, vol. 31, no. 3, pp. 815-820, 2010.

[19] X.-Z. Wu, X.-X. Liu, Z.-Z. Liang, X. You, and M. Yu, "Experimental study of fractal dimension of AE serials of different rocks under uniaxial compression," Rock and Soil Mechanics, vol. 33, no. 12, pp. 3561-3569, 2012.

[20] L. Zhang, M. Ren, S. Ma, Z. Wang, and J. Wang, "Acoustic emission and fractal characteristics of marble during unloading failure process," Chinese Journal of Rock Mechanics and Engineering, vol. 34, supplement 1, pp. 2862-2867, 2015.

[21] Z.-Z. Zhang, F. Gao, and X.-L. Xu, "Experimental study of temperature effect of mechanical properties of granite," Rock and Soil Mechanics, vol. 32, no. 8, pp. 2346-2352, 2011.

[22] Z. Z. Zhang, "Fractal dimension of fracture surface in rock material after high temperature," Advances in Materials Science and Engineering, vol. 2015, Article ID 468370, 6 pages, 2015.

[23] Z. Zhang, F. Gao, and Z. Liu, "Research on rockburst proneness and its microcosmic mechanism of granite considering temperature effect," Chinese Journal of Rock Mechanics and Engineering, vol. 29, no. 8, pp. 1591-1602, 2010.

[24] Z. Z. Liang, C. A. Tang, L. G. Tham, Y. B. Zhang, and T. Xu, "Influence of heterogeneity on direct tensile failure process of rocks and associated fractal characteristic of AE," Key Engineering Materials, vol. 353-358, no. 4, pp. 2321-2324, 2007.

[25] Q. Sun, Z. Zhang, L. Xue, and S. Zhu, "Physico-mechanical properties variation of rock with phase transformation under high temperature," Chinese Journal of Rock Mechanics and Engineering, vol. 32, no. 5, pp. 935-942, 2013. 

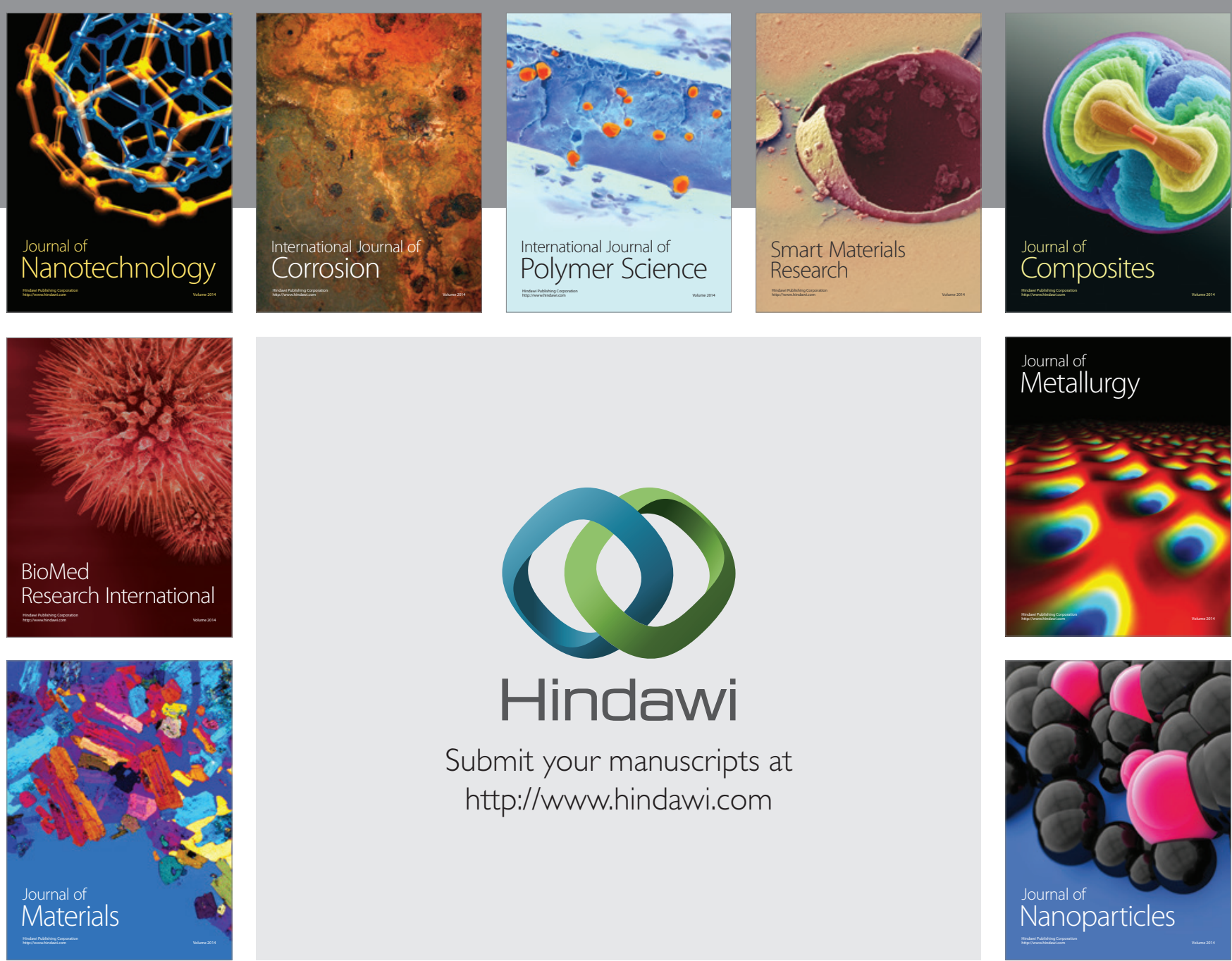

\section{Hindawi}

Submit your manuscripts at

http://www.hindawi.com

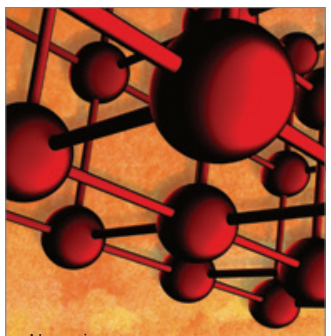

Materials Science and Engineering
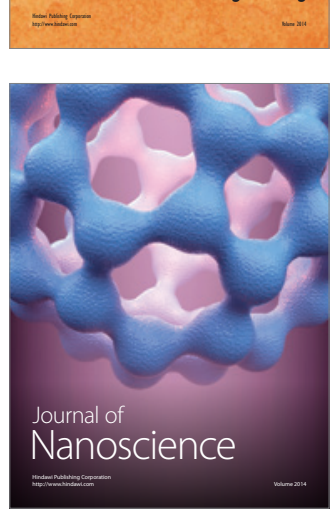
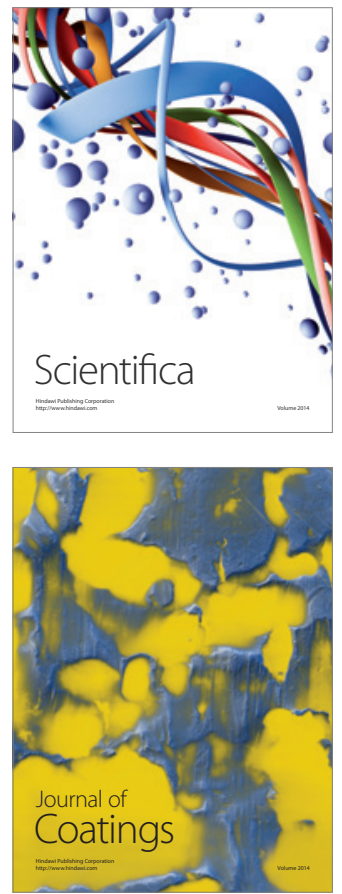
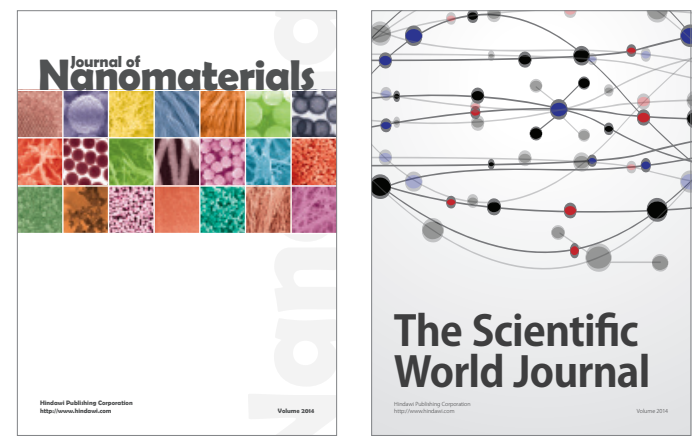

The Scientific World Journal
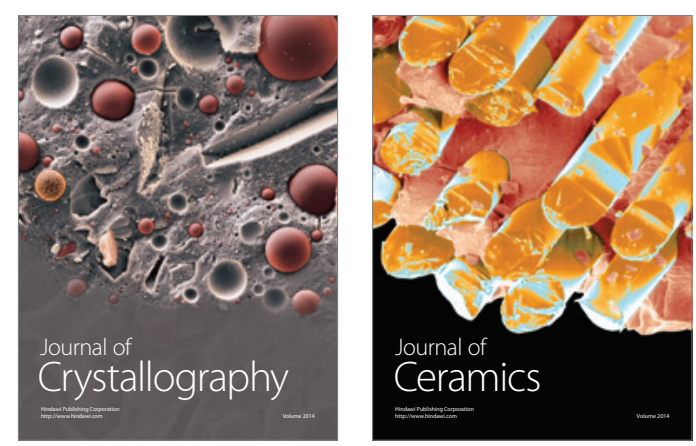
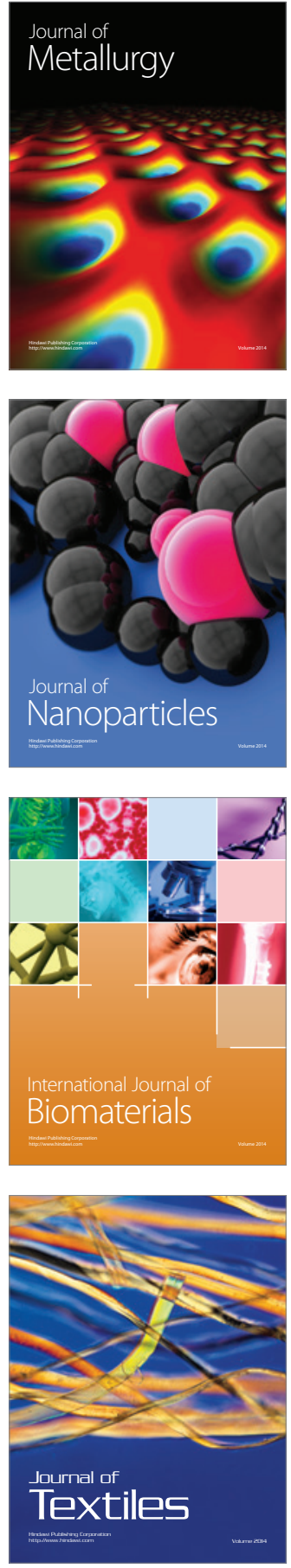